FACILITATED MATURATION OF THE INTESTINAL MICROVILLUS † 265 MEMBRANE (MVM) BY THYROXINE: A CLUE TO THE DEVELOP. Pang and MENT OF THE INTESTINAL BARRIER. Esther J. Israel, Kam chusetts General Hospita1, Boston, MA. 02114

It has been noted in the past that the MVM of newborn animals differs from adult MVM in IgG binding, enzyme activity, and membrane fluidity (MF). In this investigation we studied the influence of thyroid hormone (T4) on MVM maturation, particularly in relation to MF and IgG binding, two factors that control antigen uptake and transport in the intestine. Pregnant (17 day gestation) and 11 day old rats were given intraperitoneal $T 4(50 \mathrm{mcg} /$ $100 \mathrm{~g}$ body weight) for three successive days. Control and T4treated rats delivered normally and the MVM of the newborns (37 treated, 82 controls) and the 14 day olds ( 15 treated, 21 controls) were examined for enzyme activities. Results confirme that sucrase activity can be induced and lactase activity is depressed by $\mathrm{T} 4$ induction. MF was performed using electron spin resonance spectroscopy. IgG binding to $0.2 \mathrm{mg} / \mathrm{ml} \mathrm{MVM}$ protein was done using 125 I-rat IgG. Results indicated that: 1) MF is decreased (MVM is more organized) in $T 4$-treated newborns; 2) IgC binding is decreased in T4 treated animals as compared to controls ( $13 \%$ vs $20 \%$ in newborns and $19 \%$ vs $43 \%$ in 14 day olds at $2 \mathrm{mcg} / \mathrm{ml} \mathrm{IgG})$. IgG binding to MVM is concentration dependent and saturable (range .17-100 $\mathrm{mcg} / \mathrm{ml} \mathrm{IgG)} \mathrm{in} \mathrm{all} \mathrm{groups,} \mathrm{demonstrating}$ specificity of binding. In conclusion, $\mathrm{T} 4$ induces MVM maturational changes, particularly decreased MF and decreased IgG binding, factors important in macromolecular uptake. This may play a role in mucosal host defense in the newborn period.

\section{ISOLATION AND CULTURE OF FETAL LUNG ENDOTHELIAL}

266 CEILS. James H. Jose, Martin Post and Barry T. Smith Endothelial cells are one of the three major cell types of the lung parenchyma and serve as the lung's interface with the circulation. These clls have been previously isolated from circulation. These cells have been previously isolated from adult lumg. We have now succeeded in isolation and culture of (term $=22$ d) fetal rats, minced, and dissociated into individual cells with trypsin. Fibroblast numbers are reduced by an initial attachment to plastic culture flasks for $1 \mathrm{hr}$, after which the remaining cells are centrifuged and incubated as a pellet for $1 \mathrm{hr}$ at $370 \mathrm{C}$. The cells are then resuspended and injected into collagen sponges (Gelfoam ${ }^{R}$ ). Endothelial cells and some fibroblasts float free of the sponges and attach to the underlying flask over the next $24 \mathrm{hr}$. The fibroblasts are then eliminated by trypsinizing the attached cells and allowing the fibroblasts to attach to a fresh tissue culture flask for $3 \mathrm{hr}$, following which a pure fraction of endothelial cells remain and are replated. These cells are identified by their characteristic "cobblestone" morphology and positive stain for factor VIII by immofluorescenœ. There is strong contact inhibition which diminishes after one week in culture. This method will provide a means to study the role of the endothelial cell in fetal lung development.

(Supported by NIH grants HL-27372 and HL-27352)

POSTATAL ACCUMULATION OF ADENINE NUCLEOTIDES IN RAB-

267 BIT LIVER MITOCHONDRIA AND THE DEVELOPMENT OF CITRUL267 LINE SYNTHESIS. Richard T. Kelley and June R. Aprille.
ufts University, Dept. of Biology, Medford, MA 02155 . Liver mitochondria (mito) accumulate adenine nucleotides right after birth thereby greatly increasing the matrix ATP+ADP+AMP content (BBA: 681:300, 1982). Bioenergetic function is also enhanced. Overall, there is a large increase in matrix ATP that might be expected to stimulate ATP-dependent pathways within the mito. Carbamyl phosphate synthetase and ornithine carbamyltransferase are enzymes of the urea cycle that are localized in the matrix; they catalyze citrulline (CIT) synthesis from ornithine, $\mathrm{NH}_{3}$, and $\mathrm{CO}_{2}$ in an ATP-dependent reaction sequence. We investigated whether the postnatal increase in the matrix ATP pool size affects CIT synthesis. Mito were isolated from rabbit pups at birth and at $2 \mathrm{hrs}$ of age. ATP, ADP and AMP were determined enzymatically in PCA extracts. CIT synthes is (assayed by ${ }^{14} \mathrm{CO}_{2}$ fixation) increased between birth and $2 \mathrm{hrs}$, from $1.38+.35$ to $2.40+$ $.26 \mathrm{umol} / \mathrm{hr} / \mathrm{mg}$ mito protein. The matrix ATP+ADP+AMP pool size $26 \mathrm{umol} / \mathrm{hr} / \mathrm{mg}$ mito protein. The matrix ATP+ADP+AMP pool size
$(\mathrm{nmol} / \mathrm{mg} \mathrm{mito}$ to protein) increased from $5.7+.8$ at birth to $15.1+1.6$ at $2 \mathrm{hrs}$ and the matrix ATP/ADP ratio increased from 1.47 to 3.52 . The larger adenine nucleotide pool size together with the higher ATP/ADP ratio resulted in a 3.4 -fold increase in matrix ATP concentration. Two moles ATP are required per mole CIT, so the increase in ATP appears to account for the 1.8-fold increase in CIT synthesis. Conclusion: The accumulation of adenine nucleotides and the maturation of energetic functions within the first few hours after birth allow a rapid postnatal increase in the capacity for CIT synthesis. (NIH HD 16936)
- Galactose alimentation in the pup of a diabetic 1268 MOTHER. R.M.Kliegman, S.Morton, E.Miettinen, Case Galactose(GAL) may regulate neonatal carbohydrate assimilation and may not stimulate insulin(INS) secretion. GAL may therefore stabilize glucose(GLU) metabolism in the IDM. Pups born to INS dependent diabetic dogs or controls were fed $0.6 \mathrm{~g} / \mathrm{kg}$ of GAL or GLU $(\mathrm{N}=5)$. During fasting IDM pups had equivalent blood GLU levels and systemic GLU appearance rates(Ra), but had elevated INS $(7.4 \pm 0.3$ vs $2.5 \pm 0.3 \mathrm{uU} / \mathrm{ml}, \mathrm{p}=0.01)$ compared to control pups. After GAL feeding to IDM pups, blood GAL increased and peaked to $1 \mathrm{mM}$ at $30 \mathrm{~min}$. The glycemic response in IDM pups was similar after GLU or GAL feeding. Plasma INS increased minimally in the IDM pup after GAL feedings. In contrast, INS increased 2.5 fold after GLU. Ra of GLU in IDM pups after GAL feeding peaked at $30 \mathrm{~min}$. and was lower than after enteric GLU at $30 \mathrm{~min}$. ( $81.9 \pm 6.2$ vs $106.2 \pm 8.6 \mu \mathrm{mol} / \mathrm{kg} / \mathrm{min}, \mathrm{p}=0.01)$. Ra after enteric GLU peaked at $60 \mathrm{~min}$. and again was higher $(118.2 \pm 10.5$ vs $67.7 \pm 6.7, p=0.01)$. Hepatic glycogen content increased in the IDM fed GAL compared to fasted controls ( $634 \pm 27$ vs $485 \pm 27 \mu \mathrm{mol} /$ $\mathrm{g}, \mathrm{p}=0.01$ ) while GLU feeding had 1ittle effect. GAL and GLU feeding had no effect on glycogen synthase activity but the active component of phosphorylase decreased in both IDM groups compared to fasted controls. In summary, enteric GAL alimentation in IDM dogs results in lower INS levels with comparable glycemic responses compared to GLU feeding, attenuates $\mathrm{Ra}$ and enhances net glycogen content. In the presence of fasting hyperinsulinemia, GAL alimentation may stabilize GLU metabolism without excessive INS secretion.
260 EFFECT OF SEVERE HYPOXEMIA (H) AND HYPOTENSION (HT) ON NEWBORN CEREBRAL BLOOD FLOW (CBF), AND Kotagal. Dept. of Pediatrics, Univ. of Cincinnati (Spon. James M. Sutherland).

Cerebral autoregulation (AR) is absent under certain conditions. We studied the effect of $H$ on AR of CBF in anesthetized paralyzed, ventilated newborn dogs using microspheres. Following baseline measurements $\mathrm{H}$ was produced by $\downarrow \mathrm{FlO}_{2}\left(\mathrm{PaO}_{2}<20\right.$ torr) and maintained for the duration of the experiment. In 5 antmals HT was produced by acute $\downarrow$ in blood volume resulting in
a fall of $40 \%$ in mean BP. 7H animals served as controls and had no changes in BP or CBF. 2-way ANOVA, Neuman-Keuls, Mean+SD.

\begin{tabular}{|c|c|c|c|}
\hline & \multicolumn{3}{|c|}{ Experimental $(n=5)$} \\
\hline & Baseline & $\mathrm{H}$ & $\mathrm{H}+\mathrm{HT}$ \\
\hline $\cos \mathrm{ml} / \mathrm{k} / \mathrm{min}$ & $243+57$ & $256+52$ & $89+20 * \dagger$ \\
\hline BP $\mathrm{mmHg}$ & $48+\overline{1} 1$ & $63+12$ & $39+8 *+$ \\
\hline $\mathrm{CBF} \mathrm{m} 1 / \mathrm{g} / \mathrm{min}$ & $.22 \mp .09$ & $.50+.1 \dagger$ & $.50 \mp .05+$ \\
\hline $\mathrm{CMRO}_{2} \mathrm{mg} / \mathrm{min} / 100 \mathrm{~g}$ & $1.25 \mp .6$ & $.58 \mp .3 \dagger$ & $1.6 \overline{3}+.6$ \\
\hline $\mathrm{PO}_{2}$ (torr) & $239 \mp 34$ & $14+1.2 \dagger$ & $20 \mp 2 \dagger$ \\
\hline $\mathrm{PCO}_{2}$ (torr) & $38 \overline{+2}$ & $39 \overline{+2}$ & $31 \mp 5 *+$ \\
\hline
\end{tabular}
between periods, $\star_{\mathrm{P}}<0.05$ exp vs control. Thus, 1) severe $H$ produces a marked increase in CBF primarily due to cerebral vascular resistance (CVR), 2) in spite of $\uparrow$ $\mathrm{CBF}$ and maximal tissue oxygen extraction, $\mathrm{CMRO}_{2}$ falls by $50 \%$, 3) unlike the adult, AR of CBF in preserved after $10^{\prime}$ of severe $\mathrm{H}, 4)$ the further fall in CVR due to $\mathrm{HT}$, after maximal vasodilatation due to $H$, suggests that the mechanisms for $H$ and $H T$ vasodilatation on the cerebral vasculature may be different.
270 IMPULSE ACTIVITY DIFFERENTIALLY REGULATES LEU270 ENKEPHALIN AND CATECHOLAMINE (CA) CHARACTERS IN I.B. Black, (SPON. P.A.M. Auld), Develop. Neuro./ Perinatol. N.Y.H.-Cornell Medical Center, New York, New York 10021 Trans-synaptic impulse activity has long been known to increase CA biosynthesis and CA synthetic enzymes in the adrenal medulla. Since opiate peptides are co-stored and co-released with $\mathrm{CA}^{\prime} \mathrm{s}$ in medullary cells, and since medullary opiate peptides may be important modulators of the sympathoadrenal stress response, we examined trans-synaptic regulation of the putative peptide neurohumour, leucine-enkephal in (ENK) of the putative peptide neurohumour, leucine-enkephal in (ENK)
and the CA enzymes, tyrosine hydroxylase (TH) and phenylethanolamine- $\mathrm{N}$-methyl transferase (PNMT) in the rat adrenal medulla in vivo and in vitro. Surgical denervation of the adrenal or pharmacologic blockade of synaptic transmission, treatments known to decrease CA traits, increased ENK-like immunoreactivity to $150 \%$ of control. Medullae explanted to culture exhibited a 50 fold rise in ENK in 4 days, whereas TH remained constant, and PNMT decreased to a new baseline. Depolarizing concentrations of $K$ prevented the accumulation of ENK while not affecting TH or PNMT. Our studies suggest of ENK while not affecting TH or PNWT. Our studies suggest tially regulated by impulse activity and depolarization in the adrenal medulla. Independent regulation of adrenal neuropeptides and CA enzymes may allow new therapeutic approaches to shock, hypoxemia, or stress-induced analgesia through alteration of specific neurohumoral mechanisms. (Supported by NIH Grants HL00756, NS10259, and HD12108). 